\title{
Customer Feedback Utilization: The Case of a Telecommunication
}

\author{
Article by Annie Babah Alargi \\ Management, Texila American University, Ghana \\ E-mail:annibabah@gmail.com
}

\begin{abstract}
Purpose: The purpose of this paper was to investigate how data from customer feedback is utilized by the Telco and translated into strategies and competency based actions to address customer needs and service concerns.

Problem statement: Whereas customers are displeased with cost of services, limited network service coverage, long queues and poor connectivity, this Telco have focused on basic elements of service including greeting, smiling, making the customer feel comfortable at their service centres and enticing them with discounts and promotions.

Methodology: A mixed method of qualitative and quantitative research was used. Using purposive sampling, two homogeneous groups were selected; the first was semi-structured interviews with five managers. Secondly, closed ended questionnaires were dispensed to a quota sample of 20 affluent customers.

Findings: This Telco giant mainly collects customer feedback through call centres, social media, direct customer engagement, close-loop feedback system. However the feedback is not adequately utilized because it does not favour the Telco relatively to profit optimization and in some cases involve new system infrastructure.

Research limitations: The study focused on one giant Telco within the industry in Ghana believed to have best practices that can be generalised to other Telcos in market. Selection of only affluent customers represents a deeper understanding of customer satisfaction issues.

Practical implications: whereas this Telco believes that it is delivering the best of service to its customers by smiling at them, greeting, making them feel welcome and rewarding them with promotional gifts and discounts, the customers on the other hand, believes that the service the Telcos are offering are "must be" and that, these are basics of service, hence what they expect including improved network coverage, decrease in high cost of voice calls, seamless connectivity and zero interruptions in service transactions are not what they are actually experiencing to enable their satisfaction.

Originality: While this paper is the first to consider customer feedback utilization of a conglomerate Telco in Ghana, it also measured the service competency based actions that is implemented to provide superior service experiences to its customers.
\end{abstract}

Keywords: customer service experience, service value, service management, customer expectations, customer desires, customer delight.

\section{Introduction}

In Ghana, there seem to be a gap between the telecommunication organizations' understanding of what customers expect and the real customer experience. This realization is coming from the fact that whereas customers are complaining about their experiences, most of the telecommunication companies are spending huge sums of investments and activities on promotions that do not seem to meet the customers' needs. Comparing the customer expectation and the telecommunication promotional offer, there seem to be no correlation between the two.

Ghana is proud to have five (5) well-recognized telecommunication companies (Telcos). All these Telcos claim to be customer centred and offer the best services to their customers. All these TELCOs 
offer similar products and services, mainly mobile phone connectivity, internet platform, mobile money transfer. All of these TELCOs have Customer Service points where customer complaints are addressed and feedback received. The activities of the TELCOs are monitored and controlled by the National Communication Authority (NCA).

Going beyond service quality improvements, these Telcos offer various promotional activities and giveaways to their customers with the view to delighting them. Meanwhile, customers feel taken for granted because of general service dissatisfaction. High customer dissatisfaction makes them complain to the National Communication Authority (NCA); resulting to fines imposed on the Telcos.

\section{Customer experience}

For their basic needs, customers using the services of Telcos want reliable connectivity, clarity of talk in case of telephones and good internet speed wall all of them coming at an internationally acceptable price. As of now, customers are still displeased with certain aspects of services provided by the Telcos. These include cost of airtime for voice calls, cost of internet data, charges on mobile money transactions, long queues at some service centres, poor connectivity, interruptions in voice call services and other selfservice transactions, low or poor network service coverage at certain locations in the country. All these have caused most customers to depend on two (2) or more Telcos to address their own telecommunication needs. For convenience, in some cases, customers use single phone with dual sim cards for different networks so that they can easily switch to the most reliable network at any point in time. Most of these complaints enumerated by the NCA were from customer grievances. www.ghanabusinessnews.com (May 19, 2016)

\section{The telco under study}

The Telco under study is the second to enter the Ghanaian market in 1996 but currently the number one in terms of market share, both in volume and value. It currently has a network subscriber base of approximately 17 million of Ghanaian telco consumers and employs approximately 1165 people directly. It has been operating in Ghana for over two decades having re-branded three times; the last being in 2006 when it was acquired by Investcom. It contributes largely to the service economy of Ghana with its current vision "to lead the bold new digital space". Its products include mobile money services, voice and data services and ICT services.

\section{Telco customer service activities}

Whereas customer needs seem to be clear to the average user, this Telco on the other hand have been conducting series of promotional activities with the view to attracting customers to patronise their services. These include free calls at some specific times such as weekend mid night calls; talk for less during national holidays; load a certain amount of credit and get double; and pay for other services using their mobile money platforms to receive a token airtime for voice calls.

\section{The customer experience and the telco offering gap}

A number of questions bother most people's mind over the gap between customer experience and offering from the Telco. Despite all efforts to meet customer needs, why is this Telco still not achieving that? Is the Telco really gathering true customer feedback and implementing measures to meet identified areas of customer satisfaction? Are customers' needs fast changing to the extent that the Telco is unable to meet the needs? Why is it that despite the cry for basic satisfaction; needs of customers are ignored and instead given all sorts of freebies that are not their priority? Deeper understanding of the above requires an understanding of customer feedback gathering and its utilization from this Telco giant in Ghana. 


\section{Ways of collecting customer feedback and how the telco does it}

This Telco uses a number of ways to collect customer experience feedback that has advantages and disadvantages. In most cases, using one approach does not give the needed holistic feedback for management decision making. A good approach to gathering feedback is to have a multi-channel approach. This includes the "voice of the customer" mechanism; a direct customer engagement to collect customer feedback. The "close loop feedback" where customers are called back to ascertain their service experience during their last transaction. The customer feedback and suggestion box placed at visible points across service centres. Speak-up Lines, Hotlines and Toll Free Lines used to access customer feedback. Social media platforms; e-mail system. Further, the Quest Back mechanism and the Customer Relationship Management tool (CRM) can also be used. Customer surveys could be carried out once or twice a year to ascertain their perceptions of service the Telco is currently providing against their expectations. Upsell and Cross-Sell mechanisms are other ways for collecting customer feedback. However, the Telco use a few of the tools afore-mentioned, especially the close-loop feedback and hotlines.

\section{Customer feedback utilization}

Customer feedback is the bedrock and lifeline of every organization; but not appreciated especially when they are negative. (J. Barlow and C. Moller 1996). Customer feedback, when properly utilized, enables continuous improvements in service quality and customer experience. Organization strategies must therefore embed customer concerns and suggestions where relevant to enable organisations provide the desired and expected solutions to customer needs. Customer feedback utilization involves a deeper understanding of customer insights and an appreciation of what they seek to achieve (F.F. Reichheld, HBR, 2003). Although the Telco have committed to effectively addressing customer complaints and issues within 48 hours, the question is whether they are addressing the issues to customer expectations and satisfaction.

Quality is what the customer says it is as the quality of listening has impact on the quality of service. (L.L. Berry and A. Parasuraman 1997) In this modern twenty-first century, the customer is in the driver's seat and dictates the direction, success or otherwise of businesses; organizations failing to recognise this simple fact, will soon fail to exist when they gradually lose their customers for failing to recognise customers' evolving service experience preferences and how they now choose organizations to service their needs. (Stewart Nash, customercentricity.biz)

\section{Research objectives}

The main objective of the research is to investigate and understand how this Telco giant in Ghana collect and utilize customer experience feedback to enable them provide pleasing customer service experiences.

An evaluation of preferred service that customers value and expect from this Telco versus what they actually experience from this Telco will be explored.

\section{Problem identification (Research question and sub-questions)}

The main problem of this study is that whereas the Telco believe it is delivering the best of service to its customers, the customers on the other hand, do not seem to think that they are receiving the expected or required service from this Telco. Few customer interactions have suggested that, the main customer problems for which they seek solutions from the Telco are not what the Telco are addressing or delivering to them. The National Communication Authority as the regulator has consistently reprimanded Telcos in Ghana for poor service emanating from customer complaints. The NCA has even gone ahead to introduce the porting system to give consumers choices and enable them to easily switch networks at any time, without necessarily changing their existing telephone numbers so they can access the services of any Telco they think can offer better quality of service and customer experience (www.nca.org.gh). In order 
to provide total customer satisfaction, it is necessary to carry out this research to determine whether the service this Telco in Ghana deliver to their customers are what customers actually seek or need and if so, examine the parameters for customer dissatisfaction, but if not, ascertain how this Telco utilises customer feedback to address customer service needs.

\section{Methodology}

\section{Structured and unstructured approach}

\section{Primary research - qualitative and quantitative (Mixed method)}

Social research is a natural science model of the research process applicable to the study of society. This entails research philosophy, research strategy, research design and approach. (Bryman Alan, 2016) Research process involves research philosophy, approach, strategies, and time horizon and data collection methods. (Saunders et al, 2000). An inductive approach of linking data and theory is associated with qualitative research; therefore, primary data was collected via non-probability sampling, initially using indepth semi-structured interviews to generate qualitative data. Qualitative research also included some documents as other sources of data. Quantitative research using closed-ended questions was also administered to customers of this Telco. The methodology strategy was a mix of both qualitative and quantitative data. The study adopted a mixed method approach, where the research begun with the qualitative aspects of the study. These answered the first and second research questions. Then, the quantitative study followed to answer the customer research questions.

\section{Research philosophy}

The research sought to understand the key expectations from customer feedback that constitute positive customer service experiences, their relationships and impact on customer satisfaction. Following initial literature review and my involvement with customers in satisfaction surveys as well as training and development programs involving employees, I was not completely independent to the research. The topic was approached from a perspective that collecting and utilising customer feedback appropriately is relevant to provide the necessary impetus for successful customer service experiences and satisfaction.

\section{Research approach}

An examination of how this Telco giant in Ghana collects and utilize customer feedback, an explanation of the causal relationships between the variables - the correlation between the actions of this Telco against customer expectations. Exploratory methods was used to assess how this Telco collects and utilizes customer feedback and implemented improved service actions for true customer satisfaction. Initial findings and review generated further probing to seek insight into customer feedback utilisation by this Telco giant in Ghana. (Robson, 1993).

Following from the work of other research proponents including Bain and Company (2015) on similar studies, a quantitative approach using closed ended questions was dispensed to test what feedback customers provided to this Telco under study.

\section{Research strategy}

There are typical linkages between approach and strategy. (Robson 1996) Case studies lend themselves to exploratory purposes and can provide theoretical generalisations that may be useful to predicting future trends. Approach adopted was multi-method involving analysis of customer feedback collection techniques and utilization of it for competence-based actions leading to customer satisfaction and followup interviews from which themes such as establishment of customer feedback management strategies were identified. A mix methodology strategy was used. (Saunders et al 2000). 


\section{Sampling technique}

Using purposive sampling, two homogeneous groups were selected; the first was semi-structured interviews with five heads/managers involved in primary activities of customer feedback collection, data analysis, service strategy and implementation. Secondly, closed ended questionnaires were dispensed to a quota sample of customers of this Telco. This Telco in Ghana under study was chosen because they have certain best practices and is the largest Telco in terms of percentage market shares relatively to the Telco industry in Ghana that can be used to represent all other Telcos on the Ghanaian market. Hence, 5 internal including heads/managers, from this Telco giant were taken through guided interviews and 20 individual customers surveyed through closed-ended questionnaires based on socio-demographic and cultural capital characteristics.

\section{Secondary data}

Secondary data from existing sources on this Telco giant in Ghana was also used.

\section{Data analysis}

Whereas secondary source of data supplies results data, primary data supplies current information happening in the now, which must be analysed thoroughly and compared with existing data to deduce relevant and useful findings. Data analysed extracted findings from both primary and secondary information using manual coding for qualitative data analysis and computer assisted tool for quantitative data. Averages and measures were computed for major variables to extrapolate key findings. Recommendations from Saunders et al, (2007) was followed for the data analysis.

\section{Limitations}

Suggestions from Bryman and Bell (2011) was considered to gain access to the selected Telco under study. Meeting appointments were made with heads and managers of the various service centres of this Telco visited for guided interviews. Period for guided interviews with senior management and other staff of this Telco dragged data collection, as their consent to take part in the interview was done only through approved appointments.

Customers approached at service experiences centres of this Telco did not cover the entire population of the customer base of this Telco.

Data collected from sample population both qualitatively and quantitatively may not cover consistency of experiences at the different locations because of the different timings that interviews were done and questionnaires were dispensed.

\section{Results}

The study was a mixed method of both qualitative and quantitative research.

\section{Qualitative research}

On qualitative research, five respondents were sampled from this Telco including Executive team member, senior employee and branch managers from three different service locations of this Telco. $60 \%$ of female and $40 \%$ male aged between 25 and 50 years with educational background spanning first degree to masters.

The consistency of statements made by all respondents in response to question on how this Telco collects customer feedback indicates that this Telco utilizes a number of means and tools to collect customer feedback. This includes the close-loop feedback mechanism, short messaging service (sms) and in some cases, focus group discussions. The close-loop feedback is a mechanism where once the customer has an interaction with this Telco at any service touch point, a call is placed to the customer by a quality assurance agent of this Telco to evaluate the interaction with the service personnel of this Telco. Customers are asked to rate the level of service interaction on a scale of $1-10.10$ being highest and 1 
being poorest and asked to give reasons for the rating. Questions asked by the quality assurance agent includes "whether the customer was smiled at; treated right; or whether the service staff was willing to help and finally any suggestions from the customer on service improvements.

The collated results from the close-loop feedback provides an indication of the net promoter score to know whether this Telco is leading or lagging with their customer service. This is what is mainly used to appraise and measure service interaction with customers. However, the social media space as another channel for customer feedback collection was mentioned as a result of the revised vision of this Telco "To lead a new bold digital space". According to the respondents, this channel particularly enables them to track consistency or inconsistency in messaging being delivered by their service staff on their social care platform to customers.

On how customer feedback is utilized for service improvements, according to the respondents of this Telco, they have meeting platforms where they deliberate on feedback coming in from customers and prioritise the ones that needs attention in order to improve on customer service. This is also done using an action tracker which is reviewed from time to time to check status and monitor implementation of corrective actions. According to the respondents, this may involve retraining their staff sometimes or engaging in certain cross-functional level discussions and debates which will finally lead to what best decisions and executions to be done.

As a follow up question, respondents were asked whether their focus for customer feedback is mainly on the service interactions. Responses provided indicated that, in addition, quality of network, quality of distribution (location) quality of service and quality of systems in tracking one's spend on the network services were also things that were considered by this Telco to ascertain the gaps and flaws. Hence technology plays an essential part in the customer experience, they added. Respondents also mentioned using customer relationship marketing (CRM) as a tool to embed the voice of the customer and to know their customer segments to enable provide the different service experiences to them since they are unable to provide same service to all customers they confessed.

\section{Quantitative research}

Twenty (20) affluent customers of this Telco were sampled comprising $30 \%$ male and $70 \%$ female with occupation of $40 \%$ as management in corporate organizations and $60 \%$ being entrepreneurs within the ages of 25 to 50 years. All these respondents use the services of at least two networks from different Telcos. The main quantitative study on what feedback this Telco collects from their customers was researched through closed-ended questions using a Likert scale on the following parameters:

1. What informed customer choice of this Telco?

2. What are some of the things they value and will consider as their satisfaction triggers (not necessarily being currently experienced by this Telco)?

3. Whether this Telco solicits feedback from them and what feedback does this Telco solicit from them especially on service improvements and new service developments.

4. Whether there is visible improvements in service outcomes based on feedback provided to this Telco and

5. Whether they are satisfied with the services of this Telco to merit a positive referral?

On question one, a whopping $85 \%$ of respondents said their choice of this Telco was based on prior knowledge and beliefs that their expectations will be met as a result of the number of years' experience of this Telco on the Ghanaian market being the second to enter the market.

Approximately $74 \%$ of respondents said, some of the things they value that will enable their service satisfaction (not necessarily what they are currently experience from this Telco) will include privacy and security; faster and simplified service; easier connectivity, network accessibility as various locations, clarity in voice calls and value for money among others. 
As to whether this Telco solicits feedback from them and on service improvements and new service development in particular, $65 \%$ responded in the affirmative and said they have been engaged somehow ow received a text asking about their service experience.

Whether these respondents have seen or can recognise any visible improvements as far as their expectations and what they described in question two as some of what will enable their satisfaction as customers, approximately, $40 \%$ of them agreed, while $60 \%$ disagreed of any visible improvements or positive outcomes from feedback they have given to this Telco.

As to whether they are satisfied with this Telco such that they will give positive referrals to others, $40 \%$ responded in the affirmative, $10 \%$ said never while $50 \%$ said they were not sure.

A graphical representation of the quantitative data from customers is attached as appendix 1 to 7 .

\section{Discussions}

The secret to understanding customers' needs, wants and concerns is making the most of customer feedback (Chuck C, 2014). This means that collecting feedback should not be the ultimate but how to manage and take action on the feedback to improve services is most essential.

Customer feedback management is the process by which customer feedback is incorporated into operational processes. Feedback facilitates management processes designed to make it actionable. The objectives of the business determines what feedback to collect, how to analyse, how to disseminate and what actions to take. If insights from customer feedback is effectively acted upon, its value can be potentially very high. (Reichheld 2003, HBR)

From the above qualitative and quantitative analysis, it is clear that this Telco makes an effort to deliver good service experience to their customers. The net promoter score measurement gives an indication of whether customers think the service is good or bad. Customer feedback management based on the net promoter methodology is often used to increase customer loyalty and improve revenue, however it must be delivered by trained, empowered and motivated employees who are in a position to take meaningful actions to improve on customer service and relationships. (Reichheld, Frederick, Harvard Business Review 2003). Some priorities of this Telco may be misplaced in addressing pertinent customer concerns. Service improvements may involve capex investments which decision cannot be taken at the shop floor hence customer expectations needs to be managed while Executive management team continues with discussions and debates on which service improvements to give immediate attention or priority to. Customer feedback mechanism at organization and business unit level needs better integration. To gather customer feedback that enables meaningful decisions for improved services, middle management needs to have a stronger involvement in the design and implementation of the customer feedback. Central efforts must be placed on the support of managers in the interpretation and use of data that is gathered through organization wide feedback initiatives. (Caemmera, Barbara and Wilson, Alan, 2010)

The best way this Telco deem suitable in managing customer expectations is through positive physical service interactions, rewards and promotions at the expense of technological system improvements to address the cry of customers. Why would an organization spend so much budget on customer promotions and rewards than into improving network services where customer keep calling for change? Customer respondents sampled are not people who are swayed or induced by promotions; they can afford and wants right value for money and are concerned more with the satisfaction triggers than an offer of a free 10 or 30 minutes voice call or data.

The Pareto principle suggests that $80 \%$ of an organization's revenue is from $20 \%$ of its top customers and $20 \%$ of its revenue is from $80 \%$ of its low end customers. If however, a part of these $20 \%$ customers are still complaining of accessibility, voice clarity and internet speed, then one can imagine what the lower $80 \%$ customers are experiencing given that the high value $20 \%$ customers are given top most priority with relationship managers to address their concerns. Sometimes, one may be calling someone who is standing right in front of them as a way of exchanging contacts, yet the feedback from the network 
given is "the customer you are calling cannot be reached at this moment, please try again later", meanwhile, the person's phone is on, all things being equal and standing right in front of the person trying to call them.

From the analysis, approximately half of customers sampled do not appreciate the outcomes of the feedback they provide to this Telco as they do not see or recognise any visible improvements from the service they are used to. Routinely or continuously, insights collected from customer feedback enables organization learning and improvement when effectively utilized. Improving processes enables customers to appreciate the impact of their feedback thus creating customer affinity and loyalty. Minimize detractors converting them into promoters through service recovery processes. (Markey, Reichheld and Dullweber, 2009). Customer Feedback improves customer services and establish customer relationships. It puts an organization ahead of its competitors, uncovers market trends and creates positive associations with customers. (Graham Rand, 2017, Brand Quarterly) Better understanding of customer problems also leads to demands in service improvement process. (Karna and Junnonem, 2004).

Reasons why customer feedback is not effectively acted upon is because the process of making it actionable is unnecessarily complicated as lots of efforts goes into transforming feedback into something useful for decision making. Although very useful, the cost and effort required to do something with it is too great. (Kolsy and Moaz, 2003). According to this Telco, feedback collated is discussed and debated on some meeting platforms where priority is given for the implementation of some improvements over others. These "priority improvements" may not necessarily be the solutions customers are seeking but a way to manage the problem in the short to medium term.

Customer feedback at organization and business unit level needs better integration. To gather customer feedback that enables meaningful decisions for improved services, middle management also needs to have a stronger involvement in the design and implementation of the customer feedback and central efforts must be placed on the support of managers in the interpretation and use of data that is gathered through organization wide feedback initiatives. (Caemmera, Barbara and Wilson, Alan, 2010)

\section{Conclusion}

Evolving customer expectations from service organizations demand that, service innovation becomes a continuous process, which must encompass customer feedback and utilization to engineer excellent service experiences contributing to customer satisfaction and to the growth and sustainability of the Telco industry in Ghana.

Embedding the voice of the customer through utilization and implementation of actions is crucial to the degree of success of customer satisfaction, customer loyalty, customer lifetime value, customer equity, customer advocacy and ultimately sustainable business. The research evaluated the dimensions of how customer experience feedback is utilized and implemented to impact on excellent service experience delivery, leading to customer satisfaction.

Interactions with customers have suggested that, the main customer problems for which they seek solutions from the Telcos are not what the Telcos are addressing or delivering to them. Whereas customers are displeased with cost of services, limited network service coverage, long queues and poor connectivity, the Telcos have focused on the basic elements of service including greeting, smiling, making the customer feel comfortable at their service centres whilst inducing and enticing them with marketing promotions. The questions customers are asked through the close loop feedback mechanism is inadequate to enable customers fully provide their service concerns. Further, a closed-ended text messaging to ascertain customer experience with a service only enables the marks to be ticked without a true revelation of what is in customers' head.

It is apparent that this Telco giant collect feedback from customers, however, it is not utilized effectively utilized because it may involve investments or other demanding processes that the Telco is not ready to commit to. Hence, this Telco giant manages customer expectations through discounts and promotions that takes away customers mind from the expected solution to their problems or needs to 
rather focus on the enticing customer reward schemes that the Telco offer. However, are customers really satisfied even with these offers since it favours only minority of the Telco customers. Purposefully, the Telcos are only marketing their products and services and not really providing the desired solutions to customer expectations.

The ghanabusinessnews.com reported approximately 35 million mobile phone users as at May 2016 and 18 million data users from research conducted by the National Communications Authority, the regulator of the telecoms in Ghana. As at same year, Ghana's population was reported to be 27 million. This is a clear indication that a considerable percentage of Ghanaians own more than one mobile phone and use more than one Telco service. Telco customers access two or more services from different Telco companies and not from just one Telco.

Investment in customer loyalty programs, relationship marketing and know your customer programs employed by these telecom service organisations has not still yielded total positive customer experiences and satisfaction.

Personal experiences and involvement with different customers sharing their experiences in training and development and other platforms reveal the diverse customer experiences with airlines, banks, restaurants, utility, telecommunication, and other service organizations that suggests that customers do not get total satisfaction from service organizations. This is not happening because, most service organizations, in this case the Telco focus more on short to medium target achievement and profits than the need to build customer lifetime value through consistent and total solutions that meets customer total needs.

\section{References}

[1]. Bryman, A. (2016). "Business Research Methodologies", $5^{\text {th }}$ Edition, Oxford University Press

[2]. Bryman, A., and Bell, E. (2011). "Business Research Methods", $3^{\text {rd }}$ Edition, Oxford University Press Inc., New York

[3]. Bain and Company, Inc., (2015) "The Elements of Value”, Harvard Business Review Publication.

[4]. Behani R. R., Dabbagh, Hossein, and Zanjani Mehdi (2008) "Some Proposing a Concept Model of Customer Knowledge Management”, Journal of Social, Behavioral, Business and Industrial Engineering, Vol. 2, No. 2.

[5]. Brady, M. K. (2001) "Some New Thoughts on Conceptualizing Perceived Service Quality: A Hierarchical Approach", Journal of Marketing, Vol. 65, No. 3, pp. 34 -49

[6]. Cann, C. W., (1998) "Eight Steps to Building Business Relationship", Journal of Business and Industrial Marketing, Vol. 13, No. 4, pp. $393-405$

[7]. Caemmerer, Barbara and Alan Wilson (2010), "Customer Feedback Mechanisms and Organisational Learning in Service Operations," International Journal of Operations \& Production Management, Vol. 30 (3), pp. 288-311.

[8]. Christopher, M., Payne, A., and Ballanttyne, E (1993) Relationship Marketing: Bringing Quality, Customer Service and Marketing together, Oxford, Butterworth.

[9]. Fitzsimmons, J.A., and Fitzsimmons, M.J., (2001) "Service Management: Operations, Strategy, and Information Technology", McGraw Hill, New York, NY

[10]. Fitzsimmons, J.A., and Fitzsimmons, M.J., "New Service Development: Creating Memorable Experiences", Thousand Oaks, California: Sage Publications, 1999

[11]. Hamel, Gary and Prahalad, C. K. (1994), "Competing for the Future", Harvard Business Review, July - August 1994

[12]. Hallowell, R. (2006) "The Relationships of Customer Satisfaction, Customer Loyalty and Profitability: An Empirical Study”, International Journal of Service Industry Management, Vol. 7, Issue 4, pp. 27 -42

[13]. Jaakkola, E. (2009) “Service Experience Co-Creation”, Journal of Marketing, Vol. 26, Issue 2, Emerald Group Publishing.

[14]. Junnonen, Ju.a and Karna Sami (2004). "Developing Customer Feedback Process in the Construction Supply Chain", Nordic Journal of Surveying and Real Estate, pp. 476 -488. 
DOI: 10.21522/TIJMG.2015.03.02.Art010

ISSN: $2520-310 \mathrm{X}$

[15]. Joshi, A. W. and Sharma S. (2004), "Customer Knowledge Development, Antecedents and Impact on New Product Performance", Journal of Marketing 68, (October), 47 - 59.

[16]. Kotler, P. (2003) Marketing Management, Eleventh Edition, Prentice Hall, pp. 125 - 140

[17]. LaMalfa, Kyle (2010) "9 Ways to Successfully Manage Customer Feedback", May 11, 2010 (www.destinationcrm.com)

[18]. Lucas, Robert, W. (1996) "Customer Service: Skills and Concepts for Business", Times Mirror Higher Education Group, Von Hoffmann Press, Inc., USA, Pg. 138 - 188.

[19]. Markey, Rob, Reichheld Fred and Dullweber, Audrey (2009) "Closing the Customer Feedback Loop", Harvard Business Review, December 2009.

[20]. Reichland, Frederick (2001) "The Loyalty Effect: The Hidden Force behind Growth, Profits and Lasting Value", September 15, 2001, Harvard Business Review Press.

[21]. Schultze, U., and Orlikowski, W. J. (2004) "Practice Perspective on Technology Mediated Network Relations: The Use of Internet Based Self-Serve Technologies", Information Systems Research, Vol. 15, No. 1, pp. 87 - 106

[22]. Saunders, M.N.K., Lewis, P., and Thornhill, A. (2000); Research Methods for Business Students, London, Pitman Publishing. Ghana: Internet Usage and Telecommunication Report, April 24, 2013.

[23]. Wirtz, Jochen, Siok Kuan Tambyah, and Anna S. Mattila (2010), "Organizational Learning from Customer Feedback Received by Service Employees: A Social Capital Perspective,' Journal of Service Management, Vol. 21 (3), pp. 363-387.

[24]. www.africareport.com (March 9, 2016).

[25]. www.ghanabusinessnews.com (May 19, 2016).

[26]. www.MarketResearch.com.

[27]. www.allegiance.com.

[28]. www.Mckinseyinsights.com.

[29]. www.brandquarterly.com. 